\title{
Fatal road traffic accidents in Yazd province, Iran during 2011-2015
}

\author{
Mohammad Hasan Lotfi ${ }^{1}$, Hossein Lashkardoost ${ }^{2}$, Andishe Hamedi ${ }^{3 *}$ \\ 'Department of Epidemiology and Biostatistics, Shahid Sadoughi University of Medical Sciences, Yazd, Iran \\ ${ }^{2}$ Department of Public Health, School of Public Health, North Khorasan University of Medical Sciences, Bojnurd, Iran \\ ${ }^{3}$ Shirvan Center of Higher Health Education, North Khorasan University of Medical Sciences, Bojnurd, Iran
}

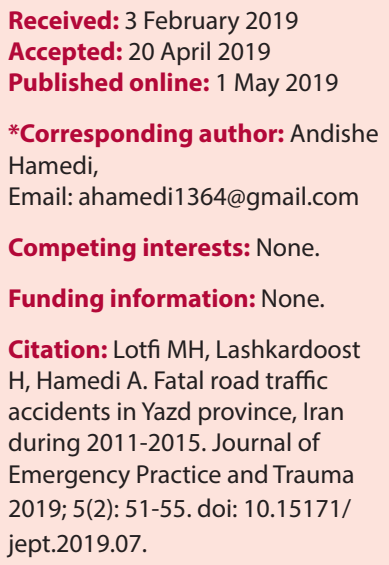

\begin{abstract}
Objective: The rate of road traffic accidents in Iran per capita and for the number of vehicles is much higher than the average in the world. The present study was conducted to investigate road traffic accidents in Yazd province during 2011-2015.

Methods: The present study is a descriptive-analytic study in which data were obtained from data collection forms related to deaths from driving accidents of forensic medicine organizations. Data were entered into SPSS version 23. We calculated the frequency, percentage, and mean indices. We used Fisher exact test for data analysis.

Results: In this research, 1437 individuals were studied. The number of deaths in men was three times more than women. Most fatal accidents occurred in the age group of 20-30 years. The most common accident which occurred during these years was the collision of vehicles with each other and in terms of the final cause of death, 1045 people died due to head injuries. In this study, we showed that the incidence decreased from 29.03 in 2011 to 22.03 in 2015.

Conclusion: According to the results of this study, the most cases of fatal accidents occurred in the age group of 20-30 years, in people with elementary education and in the summer. Therefore, preventive action is necessary by raising awareness. Keywords: Accidents, Traffic, Iran, Fatal road traffic accidents, Injury, Epidemiology
\end{abstract}

\section{Introduction}

Accidents and injuries are one of the major epidemics of non-communicable diseases in the current century (1). Accidental lesions are one of the five leading causes of death in different age groups in developed and developing countries. Unlike other illnesses, the victims of an accident are mainly from the generational group. Almost 50\% of the fatal road traffic accidents occur at the age of 15 to 44 years (2). Road traffic accidents are the result of an accident caused by any vehicle on the public transportation routes (3). Road transportation, in addition to its benefits for the nation and people, has a significant impact on people's health, such as road traffic injuries, respiratory diseases, reduced physical activity, and air pollution which affects all ages (4). Since significant changes such as changes in lifestyle and vehicle numbers have occurred; but exposure to risk factors has increased. In this regard, damages and deaths from accidents are increasing day to day (5). Road traffic accidents around the world are recognized as the main cause of disability and mortality. Death due to accidents is called death within 30 days after the incident. Road traffic accidents are causes of death in 18.8 per 100000 people worldwide. It is $12 \%$ of the burden of diseases (6). Road traffic accidents in the world annually kill 3000 people and injure about 137000 people. It is the ninth cause of the burden of diseases in the world; According to the World Health Organization, this rating will be the third cause of the burden of diseases in $2030(7,8)$. It imposes many physical, psychological, and economic consequences on society and families (4). The pattern of fatal road traffic accidents varies greatly between developed and developing countries. In the past four decades, fatal road traffic accidents had a downward trend in high-income countries, while this trend has increased in other countries including Iran (9). The death rate from road traffic accidents in Iran per capita and for car numbers is much higher than the average in the world $(10,11)$. Road traffic accidents in Iran, with an annual incidence of 30-40 people per 100000 people in 2005 , are the second cause of death and the first cause of lost life $(12,13)$. The percentage of accidents in different provinces of Iran is different. A study conducted on the burden of diseases caused by road traffic accidents in Yazd province in 2010 showed that the total burden of 
diseases caused by road traffic injuries was 12478 years, which estimated $87.41 \%$ due to premature death and $12.59 \%$ due to disability (14). Road traffic accidents did not have the same distribution across the road network. Road engineering plays an important role in reducing the frequency and severity of road traffic accidents, and the first necessity of health and promotion of life expectancy in Iran is the reduction and control of accidents. Therefore, accidents worldwide, especially in developing countries, including Iran, need to be prioritized. Unfortunately, the damage caused by traffic accidents in our country neither is massive and shocking, nor is growing yearly, and we need accurate information in order to prevent and control the damage caused by these incidents. The present study investigates the epidemiological trend of road traffic accidents in Yazd province during 2011-2015.

\section{Methods}

The present research was a descriptive-analytic study. We collected data on deaths from driving accidents recorded at the forensic organization. In this study, we used monthly road traffic accidents data in Yazd province during 20112015. Based on these forms, the frequency of car accidents was extracted based on age, sex (male/female), education, marital status, occupation, place of residence (city/village), type of vehicle used by the deceased, type of vehicle involved with pedestrians or involved with the vehicle of the deceased. Also, the frequency of trauma (head, neck, back, etc), the ultimate cause of death (bleeding, burn, choking, etc), the deceased's condition at death (driver, pedestrian, occupant), the place of death ( the location of the incident, during the transfer to a hospital, home), the type of accident (vehicle collision, collision, reversal, etc), brightness status (night, day, sunrise and sunset) and the location of the accident (inside urban, out of urban) were also examined. Yazd province is in the central part of Iran, between latitude 29 degrees 48 minutes and longitude 52 degrees 45 minutes to 56 degrees and 30 minutes of north. Based on the census of 2011, the population of Yazd was 1074428 . The sample size was based on census and included all deaths due to road traffic accidents. In this study, the mortality rate following driving accidents was calculated in 2011-2015. According to the population of Yazd province in 2011 and the rate of growth over the years, by the Statistical Center, we calculated the population of Yazd province during 2011-
2015 and considered it as the denominator population in the calculation of the incidence. We reported the incidence rate per 100000 populations. In this study all the information of individuals was kept confidential. For analyzing the data, we used frequency indices, percentage and mean. We applied Fisher exact test using SPSS version 23 with a $95 \%$ confidence level.

\section{Results}

In this research, 1437 people who died due to road traffic accidents during 2011-2015 were studied. In general, the number of deaths in men was three times more than women. The mean and standard deviation of the age of the deceased were $37.6 \pm 21.8$ years, and the most cases were $20-23$ years old. In this study, $65.6 \%$ and $34.4 \%$ of the accidents happened to married people and single people, respectively. Also, $81.7 \%$ of the people were residents of the city and $18.3 \%$ lived in the village. The distribution of mortality and the incidence rate of road traffic accidents in Yazd province by sex per 100000 populations during 2011-2015 are shown in Table 1.

The highest mortality rates were in individuals with primary (24\%) and post-secondary education (21.8\%). Based on the seasonal distribution, the highest accident rate was $29.7 \%$ for the summer and $21.2 \%$ for the winter. Also, the highest mortality rates for months in these 5 years were September and then July and the lowest was January. In terms of the ultimate cause of death, 1045 people died from head injuries. Between these, burn was the lowest cause of death. Figure 1 shows the mortality rate of road traffic accidents in terms of ultimate cause of death during 2011-2015.

According to the extracted information, head and neck were at a greater risk of damage, which occurred in $88 \%$ of cases, but back and spine had the lowest frequency. Among the dead people, $50.9 \%$ of them died at the scene of the incident. Other cases died in the hospital, during transfer to the hospital and at home, respectively. Figure 2 shows the mortality rate of road traffic accidents according to the location of deaths during 2011-2015.

Also, the most mortality rate of road traffic accidents occurred during the day. Figure 3 shows mortality of road traffic accidents according to the brightness status during 2011-2015.

Concerning the deceased's condition, most deceased were vehicle drivers. Occupants and pedestrians were in the

Table 1. The incidence mortality rate of road traffic accidents in Yazd province per 100000 populations during 2011-2015

\begin{tabular}{|c|c|c|c|c|c|c|c|c|c|}
\hline \multirow{2}{*}{ Years } & \multicolumn{3}{|c|}{ Population } & \multicolumn{3}{|c|}{ Number of deaths } & \multicolumn{3}{|c|}{ Mortality rate } \\
\hline & Man & Woman & Total & Man & Woman & Total & Man & Woman & Total \\
\hline 2011 & 553564 & 520864 & 1074428 & 265 & 90 & 355 & 47.87 & 17.27 & 29.03 \\
\hline 2012 & 554093 & 521360 & 1075453 & 223 & 89 & 312 & 40.2 & 17.07 & 29.01 \\
\hline 2013 & 554103 & 521371 & 1075474 & 206 & 61 & 267 & 37.17 & 11.69 & 24.82 \\
\hline 2014 & 554114 & 521381 & 1075495 & 206 & 60 & 266 & 37.17 & 11.5 & 24.73 \\
\hline 2015 & 554125 & 521392 & 1075517 & 176 & 61 & 237 & 31.76 & 11.69 & 22.03 \\
\hline
\end{tabular}




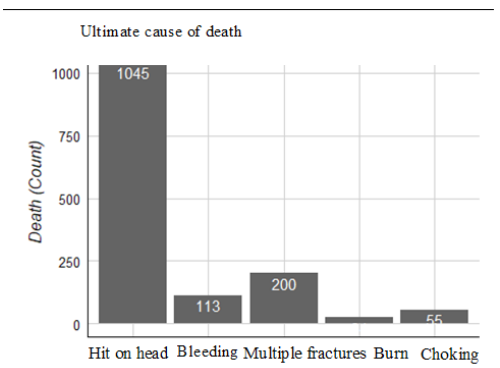

Figure 1. The mortality rate of road traffic accidents in terms of ultimate cause of death during 2011-2015.

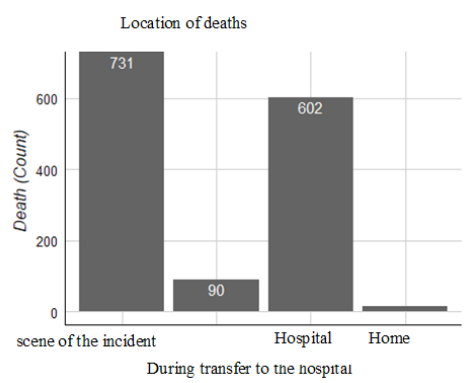

Figure 2. The mortality rate of road traffic accidents according to the location of deaths during 2011-2015.

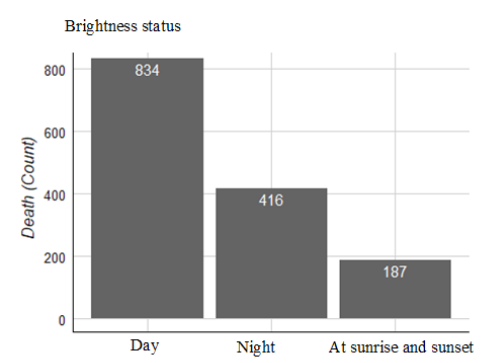

Figure 3. The mortality of road traffic accidents according to the brightness status during 2011-2015.

next ranks. The most common accidents which occurred during these years were vehicle collision, vehicle turn over and then vehicle collision with pedestrian, which accounted for $48.9 \%, 29.2 \%$ and $17.7 \%$, respectively. The most common ways to transfer the deceased to the hospital during these years were by ambulance (99.2\%), passing vehicle $(0.7 \%)$ and police car $(0.1 \%)$.

In this study, there was a significant relationship between the location of death and the location of the accident $(P<0.001)$. The results showed that in the out-of-town accidents, $81.4 \%$ of the deceased died at the scene of accident, while this proportion was $18.6 \%$ in urban accidents. Also, there was a significant relationship between the location of death and ultimate cause of death, so that $73.9 \%$ of people with head injuries lost their lives at the scene of the accident $(P<0.001)$. Table 2 shows the relationship between the location of the death with the location of the accident and the ultimate cause of death. In addition, in the present study, there was not a significant relationship between the deceased's condition (driver, passenger or pedestrian) with head and face injuries $(P=0.75)$, neck injury $(P=0.18)$, chest and abdomen injury $(P=0.5)$, back and spine injury $(P=0.48)$, pelvic impaction $(P=0.09)$, but there was a significant relationship with impact on the upper extremity $(P=0.01)$, and impact on the lower extremity $(P=0.003)$.

\section{Discussion}

The present study showed that most victims of road traffic accidents were men. Given that men spend more hours outdoors than women, and as the use of heavy vehicles and motorcycles is not common among women, we can conclude that this group is more likely to be exposed to road traffic accidents. Other studies have reported similar results $(6,15)$. In this study, we also showed that the highest mortality rate was in the age group of 20-30 years. Among the possible causes, the followings can be mentioned: the abundance of motorcyclists and lack of proper use among adolescents and young people, lack of certificates, inappropriate road and street conditions, no installation of the camera for speed control. Our findings are in line with other studies (16). A study conducted by Taravatmanesh et al showed that the highest mortality rate was among young people in the age group of 15 to 24 years (12). This finding is inconsistent with our results in which the highest mortality rate was for the elementary level of education. The study conducted by Bahadorimonfared et al also confirms our results (11). This study also showed that people with university education had a high mortality

Table 2. The relationship between location of the death with the location of the accident and ultimate cause of death

\begin{tabular}{|c|c|c|c|c|c|c|}
\hline \multicolumn{2}{|c|}{ Location of the death } & \multirow{2}{*}{$\frac{\text { Scene of accident }}{69(18.6)}$} & \multirow{2}{*}{$\begin{array}{c}\text { During transfer to the hospital } \\
12(29.3)\end{array}$} & \multirow{2}{*}{$\begin{array}{c}\text { Hospital } \\
175(64.8)\end{array}$} & \multirow{2}{*}{$\frac{\text { Home }}{2(50)}$} & \multirow{3}{*}{$\begin{array}{l}\text { P value } \\
<0.001\end{array}$} \\
\hline Location of the & Urban & & & & & \\
\hline accident & Out-of-town & $301(81.4)$ & $29(70.7)$ & $95(35.2)$ & $2(50)$ & \\
\hline \multirow{5}{*}{$\begin{array}{l}\text { Ultimate cause } \\
\text { of death }\end{array}$} & Hit on head & $540(73.9)$ & $66(73.3)$ & $425(70.6)$ & $7(58.3)$ & \multirow{5}{*}{0.001} \\
\hline & Bleeding & $44(6)$ & $10(11.1)$ & $58(9.6)$ & 0 & \\
\hline & Multiple fractures & $108(14.8)$ & $12(13.3)$ & $77(12.8)$ & $3(25)$ & \\
\hline & Burn & $38(5.2)$ & $2(2.2)$ & $38(6.3)$ & $1(8.3)$ & \\
\hline & Choking & $1(0.1)$ & 0 & $4(0.7)$ & $1(8.3)$ & \\
\hline
\end{tabular}

*Significant at 0.05 . 
rate. Evident shows the number of death by accident will reduce in people with higher level of education (17). This finding contradicts our results. The highest mortality rate was related to the summer season and in September and July. Summer holidays and busy roads, tourism situation in Yazd as well as provincial travel can be the cause of increased accidents. These findings are consistent with the results of the study conducted by Erfanpoor et al (18). Conversely, a study conducted by Taravatmanesh et al indicated that the most frequent seasons in which the accidents happened were spring and autumn (12). In this study, most people died at the scene of the incident, then in the hospital, during their transfer to the hospital and at home. We also found a significant relationship between the location of death and the location of the accident $(P<0.001)$. The results showed that in the out-of-town accidents, more deaths occurred at the scene of the accidents; while the ratio was lower for urban road accidents. Since most of the deceased were transferred to the hospital by ambulance, it can be attributed to the death of more deceased at the scene of the accident, in extraordinary accidents. Also, we found a significant relationship between the location of death and the ultimate cause of death in this study $(P<0.001)$. In this regard, $69.9 \%$ of the people who had head injury also died in the scene of the accident. Other studies have reported similar results (16). But a study conducted by Sanaei-Zadeh et al showed that most people died in the hospital (19). In our study, more deceased were drivers, then occupants and pedestrians. These studies, unlike our findings, show that more deaths are related to passengers and pedestrians (20). Our findings revealed that the majority of the accidents occurred during the day. Other studies confirm our results $(21,22)$. In this study, the most common type of accident during these years was related to vehicle collisions. However, the study conducted by Hamzeh et al contradicts our results (23). In our study, there was no significant relationship between the deceased's condition and the location of accidents $(P=0.75)$. So the most probable cause of death was a hit on the head. About $87.6 \%$ of drivers, $89 \%$ of pedestrians and $87.9 \%$ of vehicle occupants had a hit on their heads. This finding is in line with the results of another study (24). It has also been shown in many studies as well as our research that the head and neck were at a greater risk of damage (24). In this study, we showed that the incidence of mortality from road traffic accidents decreased from 29.03 in 2011 to 22.03 in 2015 . A study on the mortality rate due to traffic accidents in Iran also reported a decrease in incident events during 2005-2014 (25). But from 1997 to 2005 we had an increase in the death rate from traffic accidents (26).

\section{Conclusion}

The decrease in fatal road traffic accidents during 20112015 in Yazd province suggested that this reduction can be attributed to the tightening of traffic regulations and enforcement, construction of safer roads and cars. Also, educational programs by using mass media have a significant role in reducing the incidence of deaths from accidents.

\section{Acknowledgments}

We would like to express our thanks to the forensic organization that assisted us in conducting the research as well as providing the required data.

\section{Ethical issues}

This study was approved by ethical committee of Shahid Sadoughi University of Medical Sciences, Yazd, Iran (Ethics code: IR.SSU.SPH.REC.1395.123).

\section{Authors' contributions}

MHL: Study concept and design. AH: Study supervision, data analysis, interpretation of the data and revision of the manuscript. HL: Study supervision, data gathering, data analysis and interpretation of the data.

\section{References}

1. Soodejani M, Shirani Faradonbeh R, Hashemi SA, Zahedi A, Dehghani A. Epidemiology of accidents and injuries in the city of Lordegan in 2012: a short report. Journal of Rafsanjan University of Medical Sciences 2015; 13(9): 91722. [In Persian].

2. Rasouli MR, Nouri M, Zarei MR, Saadat S, RahimiMovaghar V. Comparison of road traffic fatalities and injuries in Iran with other countries. Chin J Traumatol 2008; 11(3): 131-4. doi: 10.1016/s1008-1275(08)60028-0.

3. Naghavi M, Shahraz S, Bhalla K, Jafari N, Pourmalek F, Bartels D, et al. Adverse health outcomes of road traffic injuries in Iran after rapid motorization. Arch Iran Med 2009; 12(3): 284-94.

4. Allock A, Agnihotri AK, Sulakshana S, Goorah D. Fatal road traffic accidents in Mauritius (2006-2011) - a retrospective study. Arch Med Biomed Res 2016; 3(1): 32-8. doi: 10.4314/ ambr.v3i1.5.

5. Maraci MR, Tabaresfahani M. The burden of road traffic injuries in Isfahan, Iran in 2010. Journal of Kerman University of Medical Sciences 2013; 20(5): 505-19. [In Persian].

6. Bhalla K, Naghavi M, Shahraz S, Bartels D, Murray CJ. Building national estimates of the burden of road traffic injuries in developing countries from all available data sources: Iran. Inj Prev 2009; 15(3): 150-6. doi: 10.1136/ ip.2008.020826.

7. World Health Organization (WHO). Global Status Report on Road Safety 2013: Supporting a Decade of Action. Geneva: WHO; 2013.

8. Rezapur-Shahkolai F, Naghavi M, Vaez M, Shokouhi M, Laflamme L. Injury incidence, healthcare consumption and avenues for prevention: a household survey on injury in rural Twiserkan, Iran. Public Health 2009; 123(5): 384-9. doi: 10.1016/j.puhe.2009.03.010.

9. Ning P, Schwebel DC, Huang H, Li L, Li J, Hu G. Global 
progress in road injury mortality since 2010. PLoS One 2016; 11(10): e0164560. doi: 10.1371/journal.pone.0164560.

10. Moradi A, Soori H, Kavousi A, Eshghabadi F. Methods for studying of frequency, spatial distribution and severity of traffic crashes related to pedestrians in urban areas: a review article. Payesh 2016; 15(6): 639-52. [In Persian].

11. Bahadorimonfared A, Soori H, Mehrabi Y, Delpisheh A, Esmaili A, Salehi M, et al. Trends of fatal road traffic injuries in Iran (2004-2011). PLoS One 2013; 8(5): e65198. doi: 10.1371/journal.pone.0065198.

12. Taravatmanesh S, Hashemi-Nazari SS, Ghadirzadeh MR, Taravatmanesh L. Epidemiology of fatal traffic injuries in the Sistan and Baluchistan province in 2011. J Saf Promot Inj Prev 2015; 3(3): 161-8.

13. Samadirad B, Khodadoost $M$, Sadeghi-Bazargani $H$, Shahedifar N, Heydari ST, Gholamzadeh S. Epidemiology of Fatal traffic injuries registered in east Azerbaijan and Fars forensic medicine organizations: the research protocol. Journal of Clinical Research \& Governance 2016; 5(1): 1-7. doi: 10.13183/jcrg.v5il.193.

14. Vakili M, Mirzaei M, Pirdehghan A, Sadeghian M, Jafarizadeh M, Alimi M, et al. The burden of road traffic injuries in Yazd province-Iran. Bull Emerg Trauma 2016; 4(4): 216-22.

15. Souri H, Akbari M, Eini E, Zali AR, Naghavi M, Kordi Borujeni E. Epidemiology of nonfatal accidents in Iran. Advances in Nursing \& Midwifery 2008; 18(60): 45-50. [In Persian].

16. Fallahzadeh H, Dehgani A. Epidemiology of road traffic mortality and injuries in Yazd, Iran during 2003-2008. Chin J Traumatol 2011; 14(5): 293-6. doi: 10.3760/cma.j.is sn.1008-1275.2011.05.007.

17. Whitlock G, Norton R, Clark T, Pledger M, Jackson R, MacMahon S. Motor vehicle driver injury and socioeconomic status: a cohort study with prospective and retrospective driver injuries. J Epidemiol Community Health 2003; 57(7): 512-6. doi: 10.1136/jech.57.7.512.

18. Erfanpoor S, Hashemi-Nazari SS, GHadirzade MR. An epidemiology study of fatal road traffic accidents in Khorasan Razavi province in 2011. Medical Journal of Mashhad University of Medical Sciences 2016; 59(4): 2618. [In Persian].

19. Sanaei-Zadeh H, Vahabi R, Nazparvar B, Amoei M. An epidemiological study and determination of causes of traffic accident-related deaths in Tehran, Iran (during 20002001). J Clin Forensic Med 2002; 9(2): 74-7. doi: 10.1054/ jcfm.2002.0547.

20. St Bernard G, Matthews W. A contemporary analysis of road traffic crashes, fatalities and injuries in Trinidad and Tobago. Inj Control Saf Promot 2003; 10(1-2): 21-7. doi: 10.1076/icsp.10.1.21.14104.

21. Khosravi Shadmani F, Soori H, Ainy E, Zayeri F, Mehmandar M. Comparison of road traffic death occurrence within urban and metropolitan roads focusing on environmental factors. Hakim Research Journal 2012; 15(4): 339-45. [In Persian].

22. Hijar M, Carrillo C, Flores M, Anaya R, Lopez V. Risk factors in highway traffic accidents: a case control study. Accid Anal Prev 2000; 32(5): 703-9.

23. Hamzeh B, Najafi F, Karamimatin B, Ahmadijouybari T, Salari A, Moradinazar M. Epidemiology of traffic crash mortality in west of Iran in a 9 year period. Chin J Traumatol 2016; 19(2): 70-4. doi: 10.1016/j.cjtee.2015.12.007.

24. Hashemi-Nazari SS, Kazemian M, Hosseini F. Trend of five years traffic accident mortality in Khuzestan province (2006-2010). Scientific Journal of Forensic Medicine 2011; 17(2): 123-9. [In Persian].

25. Mehmandar M, Soori H, Mehrabi Y. Predicting and analyzing the trend of traffic accidents deaths in Iran in 2014 and 2015. Int J Crit Illn Inj Sci 2016; 6(2): 74-8. doi: 10.4103/2229-5151.183017.

26. Zarei MR, Rahimi-Movaghar V, Saadat S, Panahi F, Dehghanpour R, Samii A, et al. Road traffic crashes mortality and morbidity in Iran in 1997-2006. Hakim Research Journal 2008; 11(3): 42-6. [In Persian]. 